\title{
Present Status of Nanoparticle Research for Treatment of Tuberculosis
}

\author{
Shegokar Ranjita ${ }^{1}$ Al Shaal Loaye ${ }^{1}$, Mitri Khalil ${ }^{1,2}$ \\ 1 Freie Universität of Berlin, Institute of Pharmacy, Department of Pharmaceutics, Biopharmaceutics \& \\ NutriCosmetics, Kelchstrasse 31, Berlin, Germany. \\ ${ }^{2}$ Centre of Cosmetic Science and Technology, University of Siena, Via della Diana, Siena Italy.
}

Received, January 4, 2011; Accepted, April 6, 2011; April 6, 2011

\begin{abstract}
Nanotechnology has offered enormous improvement in field of therapeutics by means of designing of drug delivery systems and opened the possibility of controlling infections at the molecular level. Nanocarriers can cross biological barriers and are able to target cellular reservoirs of Mycobacterium tuberculosis (M. tuberculosis). Nanoparticle-based systems have significant potential for treatment and prevention of tuberculosis (TB). A variety of nanocarriers have been widely evaluated as potential drug delivery systems for various administration routes. Targeting the drugs to certain physiological sites such as the lymph nodes has emerged as a promising strategy in treating TB with improved drug bioavailability and reduction of the dosing frequency. Nanotechnology based rational targeting may improve therapeutic success by limiting adverse drug effects and requiring less frequent administration regimes, ultimately resulting in more patients compliance and thus attain higher adherence levels. The development of nanoparticle based aerosol vaccine is undergoing which could serve as new platform for immunization. Present article compiles the general physiological aspects of the infection along with new research uptades on nanocarriers used in prevention of tuberculosis.
\end{abstract}

\section{INTRODUCTION}

In year 1993, World Health Organization (WHO) declared tuberculosis as global emergency. Tuberculosis (TB) is a highly contagious persistent infection caused by Mycobacterium tuberculosis and Mycobacterium bovis and has highest mortality rate than any other infectious disease. Worldwide One-third of the population is infected and of these, 8 to 10 million develop active disease and 2 million die each year and serve as world's second most common cause of death after HIV/AIDS. Presence of immunosuppressive condition like diabetes, alcoholism, malnutrition, chronic lung disease \& HIV/AIDS may increase the chances of tuberculosis infection $[1,2]$. The disease presents mainly in the lungs but can also develop as extrapulmonary tuberculosis in the central nervous or circulatory systems or elsewhere in the body. Untreated active tuberculosis has a mortality rate of approximately 50\% [3-5].

Tubercle bacilli are slender, acid-fast, nonmotile gram-positive bacilli. TB bacteria remain viable in the air for a long time, eventually they get inhaled by lungs and engulfed by alveolar macrophages (white blood cells) where they start to replicate within 2 to 3 weeks [6]. In $95 \%$ of cases, the macrophages throughout the body are able to carry the bacteria without any apparent disease sign. However, if the bacteria are not completely destroyed, they remain dormant for several days and may reactivate years later.

Treatment of active TB is complex and is becoming more and more complex with the emergence of multidrug-resistant tuberculosis (MDR) and HIV infection. Available TB treatment involves daily administration of four oral antibiotics for a period of six months or more [7]. Due to the high percentage of side effects (like ototoxicity and nephrotoxicity) and the extended duration of treatment results in low patient adherence [8]. History of tubercular chemotherapy started with discovery of streptomycin in 1944 [9]. Furthermore, only a small fraction of the anti-tubercular drugs reach an alveoli which is the desired site of drug action. The development of a tubercular vaccine has different array of challenges. The bacteria are carried to lymph nodes where they are surrounded by lymphocytes in a granuloma that can persist for years, and in coming years turn in active and infectious disease state.

Corresponding Author: Dr. Ranjita Shegokar, Freie Universität of Berlin, Institute of Pharmacy, Department of Pharmaceutics, Biopharmaceutics \& NutriCosmetics, Kelchstrasse 31, 12169 Berlin, Germany; Email:ranjita@arcsindia.com 


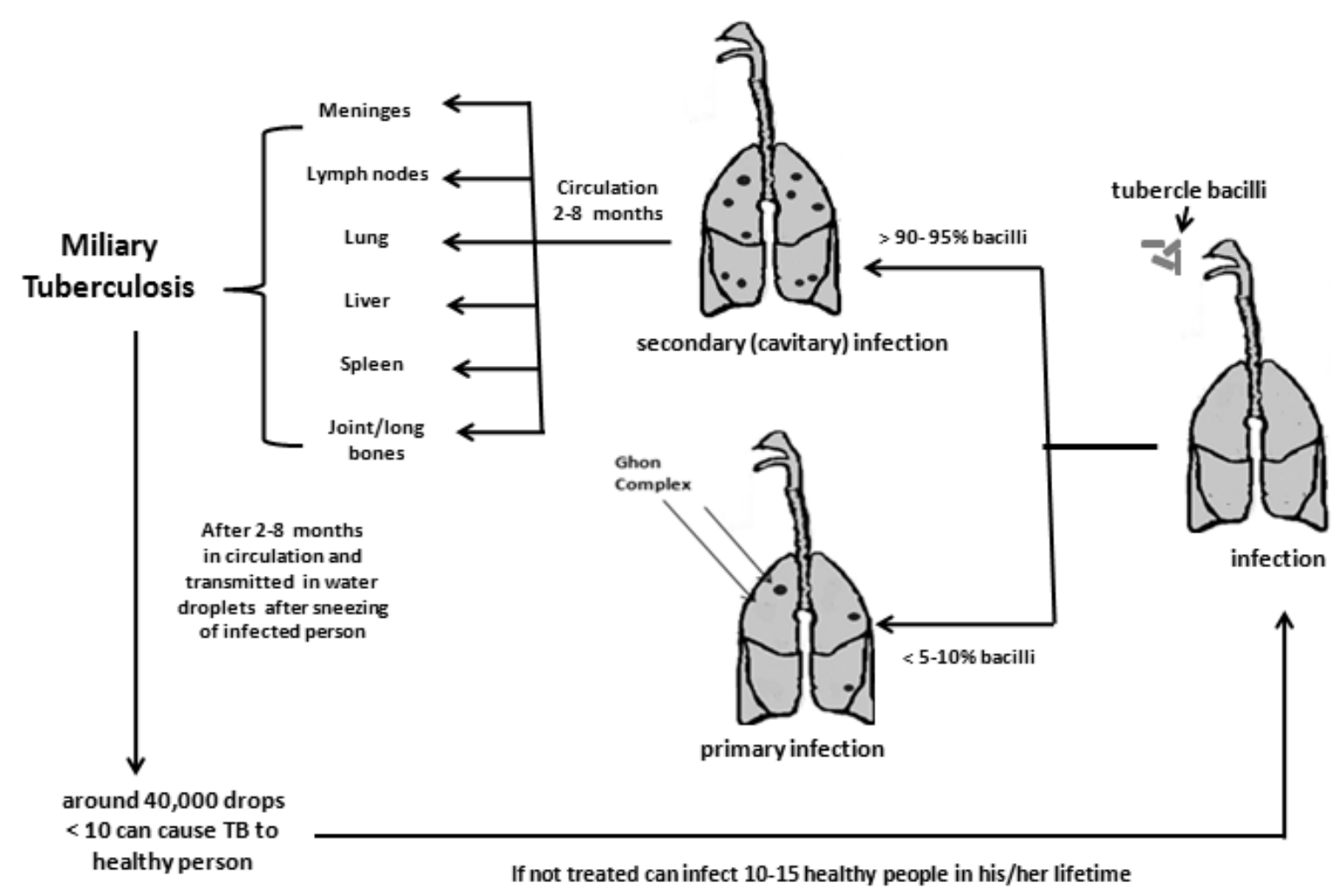

Figure1. Pathogenesis (Infection) cycle of Tuberculosis.

A successful tuberculosis vaccine must be able to induce a variety of $\mathrm{T}$ cell responses, including Th1 immune response $[10,11]$. The currently used Bacillus Calmette-Guerin (BCG) vaccine offers extremely limited protection. However, several other Mycobacterium tuberculosis antigens have been identified for potential use as vaccine antigens, including the three protein Antigen 85 complex (Ag85A, Ag85B and Ag85C), the surface exposed lipoproteins PstS (PstS-1, PstS-2 and PstS-3) and the early secretary antigenic target protein ESAT-6 [12-14]. Cationic liposomes entrapped antigenic tuberculosis ESAT-6 protein and complexed with TLR agonists were evaluated for use as a prophylactic vaccine system by Zaks research group [15]. They found to have considerable protective immunity after an aerosol challenge with virulent Mycobacterium tuberculosis [16]. Nanoscale aerosol vaccines for tuberculosis have also been developed which can perfuse throughout the respiratory pathway and also increase the amounts of drug reaching to the target alveoli. Garcia Contreas et al. have recently synthesized a particle system with both micrometer and nanometer dimensions for aerosolized delivery of the attenuated tuberculosis vaccine, BCG [17]. These dried "nanomicroparticle" vaccines were synthesized with two axes with nanoscale dimensions and a third axis with a microscale dimension. Aerosol delivery of BCG encapsulated nanomicroparticles in guinea pigs enhanced their resistance to tuberculosis infection, and generated better immune protection than a standard parenteral BCG formulation. Alternatively, the nanoparticulate delivery of aerosolized IFN- $\gamma$ via the pulmonary route has been shown to be a safe and efficient new adjunct treatment for tuberculosis $[18,19]$ when used in combination with antibiotics. The particle size-dependent cell trafficking can greatly influence particulate strategies for vaccination for mucosal or parenteral delivery [20].

Since last two decades, pharmaceutical literature discusses various aspects of drug targeting and problem associated with it. Different nanoparticulate strategies are developed to specifically deliver chemotherapeutic compounds to target disease sites. They increase drug's therapeutic index by strictly localizing its pharmacological activity to the site or organ of action. The use of nanoparticulate drug delivery 
system can improve tolerability of toxic chemotherapeutics and eventually bioavailability. The particle size between 50 to $200 \mathrm{~nm}$ is desired for maximized drug localization upon administration by inhalation. Lung has a larger surface of absorption and a thin alveolar epithelium [21]. In lungs, particle deposition takes place by inertial impaction, sedimentation and diffusion $[22,23]$. Large particles $(>5 \mu \mathrm{m})$ tend to deposit by impaction in the extra thoracic cavities, particles $(1-5 \mu \mathrm{m})$ deposit deeper in the lungs by inertial impaction and sedimentation while very small particles $(<1 \mu \mathrm{m})$ are driven by diffusion and mostly remain suspended are exhaled [24]. Nanosized particles are promising candidate as they are slowly cleared from lungs and can escape both phagocytic and mucociliary clearance. The high lung bioavailability and rapid drug absorption through the pulmonary epithelia enable the lowering of drug doses in parallel maintaining therapeutic concentration. A smaller dose combined with the absence of first pass metabolism and avoidance of gastrointestinal track is expected to lead reduced systemic side effects and enhanced tolerability. Various AntiTB drugs have been formulated in dry microparticles for pulmonary delivery, including capreomycin $[25,26]$ and para-aminosalicylic acid [27]. They provide promise in targeting TB sites, that can be directly administered to the lungs with reduced systemic side effects [28].

Various nanoparticulate systems includes, polymeric nanoparticles, lipid nanoparticles, nanosuspensions, nanoemulsions etc. and can be used to treat several types of parasitic infections [29-33]. Obviously it is very important to understand nature of biological and cellular membranes at target site, distribution and presence of drug receptors and enzymes responsible for drug metabolism. Versatility of nanoparticulate carriers also enables tailoring of drug delivery systems according to the target nature, desired pharmacokinetic profile and route of administration with reduced side effect. In present review uses of such carrier systems and their potential advantages is highlighted in tubercular chemotherapy [7, 34].

\section{Background}

Nanoparticles are defined as submicron $(<1 \mu \mathrm{m})$ colloidal particles. Monolithic nanoparticles (nanospheres) in which the drug is adsorbed, dissolved, or dispersed throughout the matrix and nanocapsules in which the drug is confined to an aqueous or oily core surrounded by a shell-like wall [35]. Alternatively, the drug can also be covalently attached to the surface or dispersed into the matrix. Nanoparticles are made from biocompatible and biodegradable materials such as polymers, either natural (e.g., gelatin, albumin) or synthetic (e.g., polylactides, polyalkylcyanoacrylates), or solid lipids (SLN ${ }^{\circledR}$, NLC $($ ) [36] in the body, the drug loaded in nanoparticles is usually released from the matrix by diffusion, swelling, erosion, or degradation.

The various advantages of nanoparticles as drug carriers include high stability (i.e., long shelf life); high carrier capacity (i.e., many drug molecules can be incorporated in the particle matrix); feasibility of incorporation of both hydrophilic and hydrophobic substances; and feasibility of variable routes of administration, including oral administration and inhalation. These carriers can also be tailor made to enable controlled (sustained) drug release from the matrix [37]. In general, the uptake of nanoparticles occurs by three mechanisms (1) transcytosis (2) intracellular uptake and transport via the epithelial cells lining the intestinal mucosa, (3) uptake via peyer's patches [38, 39].

\section{Drug delivery explored in TB chemotherapy Liposomes}

Liposomes are small spherical vesicles formed of amphiphilic lipids enclosing an aqueous core. They are widely studied as carrier systems for hydrophilic drugs [40, 41]. Gentamicin incorporated liposomes were evaluated for antibacterial activity in M. avium infected mouse model. The drug encapsulated liposomes significantly reduced the bacterial count in spleen and liver as compared to free drug. A dose-related reduction in bacterial load was observed, but no sterilization was found [42]. Similar results were reported in literature for second-line antibiotics liposomes [43-45]. Deol and Khuller developed Stealth ${ }^{\circledR}$ liposomes for the targeted delivery of anti-TB drugs to the lung. Liposomes were composed of mixture of phosphatidylcholine, cholesterol, dicetylphosphate, O-steroyl amylopectin and monosialogangliosides / distearylphosphatidylethanolaminepoly (ethylene glycol) 2000. In vivo biodistribution after intravenous administration in healthy and tuberculosis infected mice showed pronounced increase in accumulation from 5.1\% for conventional liposomes to $31 \%$ for PEGylated liposomal systems after 30 min. The accumulation extent was mainly associated to the composition of the liposomal vesicles. Drug 
uptake levels in the lungs increased to approximately $40 \%$ for the PEGylated nanocarriers when administered to pretreated infected animals only after $30 \mathrm{~min}$. whereas, 30 $50 \%$ reduction in uptake was observed for modified liposomes for accumulation in the liver and spleen [46]. Drug-loaded nanocarriers showed a significant decrease in the toxic effects when evaluated for cytotoxicity in peritoneal macrophages compared to free drugs.

A $12 \mathrm{mg} / \mathrm{kg}$ dose of liposomal drug and free (Isoniazid) INH reduced the number of $\mathrm{CFU}$ (colony formation units) in the lungs to about 3.9 and $4.5 \log$ units, respectively whereas at 10 $\mathrm{mg} / \mathrm{kg}, \quad 3.8$ and $4.3 \log$ units, respectively. Decrease in CFU was observed in similar pattern for liver and spleen. In addition, administration of sub-therapeutic doses also (4 and $3 \mathrm{mg} / \mathrm{kg}$ for INH and RIF (Rifampicin) respectively) led to a sharp decrease in CFU compared to the free drugs. The therapeutic activity of free and encapsulated INH and RIF was evaluated at both therapeutic and sub-therapeutic dose [47]. Parenteral clofazimine liposomes were [48] evaluated in acute and chronic murine infections [49]. Liposomes significantly reduced the toxicity of the drug both in vitro and in vivo and showed enhanced anti-TB activity in acute and chronic models. Administration of encapsulated drug to chronically infected mice showed total clearance of bacilli from the liver and spleen. Recent investigations reports, PYZ [50] and rifabutin containing liposomes [51].

\section{Nanoemulsions}

Nanoemulsion, many times referred as miniemulsions or sub-micronemulsions by dispersing mainly oil in water. Thermodynamically stable nanoemulsion (mean particle size of $80.9 \mathrm{~nm}$ and polydispersity index of 0.271 ) of ramipril, were developed for oral administration. In vitro drug release showed that drug release till $24 \mathrm{~h}$ from nanoemulsion and was highly significant $(\mathrm{p}<0.01)$ as compared to marketed capsule formulation and drug suspension. The relative bioavailability of ramipril nanoemulsion to that of conventional capsule was $229.62 \%$ and to drug suspension was 539.49 suggesting the use of developed ramipril nanoemulsion for pediatric and geriatric patients [52]. In another study, they investigated effect of Labrasol on self-nanoemulsification efficiency of ramipril nanoemulsion [53]. Ahmed et al., developed various parenteral o/w nanoemulsions of RIF (47 and $115 \mathrm{~nm}$ ) using GRAS listed excipients (US-FDA). The entrapment efficiency was found to be $99 \%$ with excellent stability over 3 months with slight increase in particle size and showed initial burst drug release of 40 to $70 \%$ after $2 \mathrm{~h}$ [54]. Mehta et al. performed physicochemical analysis of INH microemulsions and confirmed the release of drug from microemulsion was non-Fickian [55]. In another study, the same group studied the changes in the microstructure of Tween 80-based microemulsion in the presence of anti-TB drugs viz. INH, PYZ (pyrazinamide), and RIF [56].

\section{Polymeric nanoparticles}

In Polymeric nanoparticles, the drug is attached, entrapped or encapsulated in polymeric core and depending upon the method of preparation, they are called as nanoparticles, nanospheres or nanocapsules [57]. Polymeric nanoparticles represent an attractive alternative to liposomes [58]. Pandey et al., [59] developed sustained release RIF, INH and PYZ loaded poly(lactideco-glycolide) (PLG) nanoparticles for oral delivery. In mice, the drugs could be detected in the plasma up to 4 days for RIF and 9 days for INH and PYZ; therapeutic concentrations in the tissues were detected till 9 to 11 days after single oral dose administration of nanoparticles whereas free drugs after administration were cleared within 12 to $24 \mathrm{~h}$ from the plasma.

Five oral doses every 10 day of nanoparticles were sufficient to achieve complete bacterial clearance from the organs of TB bacillus infected mice, whereas free drugs took 46 doses to get the same results. Nanoparticles showed similar results when tested in guinea pigs [60]. In parallel, microparticles were tested and found to be less effective as compared to nanoparticles [61, 62]. In order to enhance efficiency of these nanoparticles, the surface was modified using wheat germ agglutinin [63]. Presence of lectins on surface showed improved mucoadhesion thereby faster biorecognition of carriers by glycosylated structures in the intestine and prolonged serum half life [64]. Upon oral administration in mice, these nanoparticles showed prolonged serum levels of 6-7 days for RIF, 13-14 days for INH and PYZ as compared to uncoated nanoparticles which showed 4-6 days for RIF and 8- 9 days for unmodified nanoparticles. Surface grafted nanoparticles showed detectable drug levels in lungs, liver, and spleen up to 15 days. Three oral doses of coated nanoparticles administered every 14 days (Vs. 45 daily doses of free drugs) were sufficient to give complete bacterial clearance. 
Anti-TB drugs encapsulated in nanoparticles were studied by administration via pulmonary route [65]. In guinea pigs, a single nebulization of RIF, INH, and PYZ encapsulated nanoparticles generated same effect as that of oral administration, i.e. sustained therapeutic drug levels in the plasma and in lungs was up to 6 to 8 days and 11 days, respectively. After pulmonary administration, complete sterilization in lung was observed only after administration of five doses at every $10^{\text {th }}$ day whereas to generate same effect orally 46 daily doses were required agglutinin surface modified nanoparticles required only three doses administered each after 14 days for 45 days. Passive targeting of chemotherapeutic compounds to alveolar macrophages has also been explored using pulmonary administration of nanoparticles for the treatment of tuberculosis infections [6668]. Flexibility of the nanoparticle-based formulations was further demonstrated by effective subcutaneous treatment of mice infected with M. tuberculosis [69]. A single subcutaneous dose of RIF, INH, and PYZ loaded poly-(dllactide-co-glycolide) PLG nanoparticles maintained sustained therapeutic drug levels in plasma for 32 and 36 days in lungs/spleen and resulted in complete clearance of bacteria as compared with pure drug which required daily treatment ( 35 oral doses).

Econazole and moxifloxacin encapsulated nanoparticle were prepared by the multiple emulsion and solvent evaporation technique. Potential of developed nanoparticles was evaluated individually and in combination in murine mice model in order to develop a more potent orally administered regimen for TB. Econazole and moxifloxacin loaded PLG nanoparticles showed prolonged plasma levels up to 5 and 4 days, respectively. The drugs levels in lungs, liver and spleen were lasted till 6 days as compared to pure drugs which cleared within 12$24 \mathrm{~h}$. In M. tuberculosis infected mice, only 8 doses of polymeric nanoparticles individually were sufficient to suppressed bacterial clearance where as pure drug required 56 doses daily of moxifloxacin and 112 doses twice a day of econazole. Whereas combination of two drugs proved to be significantly efficacious compared with individual drugs. Furthermore, addition of third drug RIF to this combination showed complete bacterial clearance within 8 weeks. Thus, suggesting use of developed carriers for intermittent tubercular chemotherapy [54].

Anisimova et al. prepared RIF, INH and streptomycin loaded PBCA (poly(n- butylcyanoacrylate)) and PIBCA (poly(isobutylcyanoacrylate)) nanoparticles and studied in-vitro cellular uptake in human blood monocytes in order to develop drug depot system. Promising enhancement in intracellular concentration to the extracellular concentration for encapsulated INH (4-8 fold), streptomycin (7 fold) and RIF (22-25 fold) was observed as compared to free drug INH (similar), streptomycin (undetectable) and RIF (5 times) [70].

In another work, moxifloxacin-loaded PBCA nanoparticles $(418 \mathrm{~nm})$ were prepared by anionic polymerization of poly(butyl-2-cyanoacrylate). In vitro drug release for formulation containing encapsulated moxifloxacin showed initial burst release followed by sustained drug release of $65 \%$ at end of $48 \mathrm{~h}$.

Moxifloxacin loaded NPs were more toxic than free drug when subjected to cytotoxicity assay. Cellular uptake to infected cells showed pronounced increase (2-3 fold) in the intracellular drug concentration. After IV administration, antiTB activity in mice infected with M. tuberculosis showed a significant decrease in the total mycobacterial count in the lungs suggesting potential of encapsulated moxifloxacin to kill intracellular bacilli compared to free drug [71].

Injectable PLGA (poly(lactic-co-glycolic acid)) nanoparticle-based implants were also administered subcutaneously in a murine model. A single subcutaneous dose could able to maintain drug levels in plasma, lungs and spleen for $<1$ month and bacterial counts remain almost undetectable in these organs [69]. Zahroor et al. used ionotropic gelation method to prepare alginate nanoparticles (235 nm diameter) of antiTB drug. Followed by oral administration to mice, Free drugs were cleared within 12 to $24 \mathrm{~h}$ from blood but were detectable in tissues (e.g. spleen, liver and lung) till next day. Whereas polymeric nanoparticles were detected in plasma up to 7 for ETB (ethambutol), 9 for RIF, 11 for INH and PYZ. The drug levels in organs were detectable in tissues till $15^{\text {th }}$ day [72].

Plasma life of lectins grafted PLGA nanoparticles were substantially extended to 6-14 days in mice as compared to uncoated (4-9 days) after oral and inhalation administration. Moreover, complete bacterial clearance was achieved in various organs (lungs, liver and spleen) only after 3 doses with frequency of 1 dose after each 14 days [60]. du Toit et al. developed emulsion-based polymeric nanoformulations (77-414 $\mathrm{nm}$ ) of INH-loaded using 
nanoprecipitation technique. Two kinds of precursors were used: water- or emulsion-based systems. The size of the nanoparticles can be adjusted by changing the polymer concentration; lower polymer concentration resulted in smaller particles. In vitro release studies indicated initial burst release till $2 \mathrm{~h}$ depending upon the technique used for preparation of nanoparticles [73].

INH implants after one time implantation were studied in mice by Gangadharam et al. [74]. Similarly, PYZ three times the daily dose of single PLGA polymer implant showed sustained levels up to 54 days. When investigated for chemotherapeutic efficacy showed single implant was similar to standard oral treatment with drugs (INH \& PYZ) given daily for 8 days. Kailasam and coworkers also studied implantable PLGA rod in rabbit, prepared implants could able to maintain drug levels up to 63 days [75]. Urine samples collected after 6 weeks inhibited the growth of M. tuberculosis in vitro when measured using radiometric assay. But these type of delivery systems generally require surgical operation, and has disadvantage of immobilization. Reddy et al. showed that intradermally administered, ultra-small $(25 \mathrm{~nm}$ diameter) nanoparticles were more efficient at interstitial lymphatic trafficking to lymph node resident dendritic cells than larger $(100 \mathrm{~nm}$ diameter) nanoparticles [76]. Song et al., fabricated silver nanoparticles $(<10 \mathrm{~nm})$ and studied their antimicrobial mechanism. Prepared nanoparticle showed excellent antimicrobial property for nanosilver particles [77]. Pandey et al. studied the pharmacokinetics and antibacterial effect of drug loaded nanoparticles after pulmonary administration in guinea pigs using compressor nebulizer system [59].

\section{Solid lipid nanoparticles (SLN)}

In SLN, the drug is mainly entrapped in solid lipid matrix to produce lipid nanoparticles of size range $50-1000 \mathrm{~nm}$ and they produced using hot or cold high pressure homogenization technique. It is noteworthy that the solid lipid nanoparticles display important advantages, such as the composition (physiologic compounds) and the possibility of large-scale production favored by the feasibility to avoid organic solvents in the manufacturing process [78]. A sterilizing effect was achieved after administration of solid lipid nanoparticles [79]. No tubercle bacilli could be detected in the lungs/spleen after seven doses of treatment of infected guinea pigs with drugloaded solid lipid nanoparticles. Pandey R., developed RIF, INH and PYZ loaded SLN by using emulsion solvent diffusion technique and tested against experimental tuberculosis. SLN formulations following a single oral administration to mice maintained therapeutic drug concentrations in plasma till 8 days and in the organs rich in MPS (lungs, liver and spleen) for 10 days as compared to free drugs which were cleared within 1-2 days. In M. tuberculosis H37Rv infected mice, 5 oral doses at every $10^{\text {th }}$ day of drug loaded SLNs were sufficient to completely suppress bacterial load in the lungs/spleen whereas free drug required administration of 46 daily oral doses to get same effect. SLN incorporated antitubercular drug significantly reduced the dosing frequency and improved bioavailability [79].

\section{Nanosuspensions}

Nanosuspensions, poor water soluble drugs are dispersed in aqueous phase containing stabilizing agent. Presently more than 8 candidates are in clinical trials [80]. Another drawback to the low aqueous solubility is the inability to conduct preliminary biological and clinical evaluations of new drug candidates [81]. Clofazimine, a riminophenazine compound, is an agent considered for treating patients with $\mathrm{M}$. avium infection. However, use of this drug was restricted because of its poor solubility. Clofazimine was formulated as a nanosuspension $(385 \mathrm{~nm})$ and administered to mice intravenously. It resulted in a considerable reduction of bacterial loads in the liver $(72.5 \mathrm{mg} / \mathrm{kg}$ tissue), spleen ( 81.4 $\mathrm{mg} / \mathrm{kg}$ tissue), and lungs ( $35.0 \mathrm{mg} / \mathrm{kg}$ tissue) of mice infected with M. avium [82], when compared with pharmacokinetic data, drug concentrations in these organs reached high concentrations, well in excess of the minimal inhibitory concentration for most $M$. avium strains. The effects of clofazimine nanocrystals were comparable to those of the liposomal formulation used as a control in this study. This study was specially planned to overcome the poor solubility and toxicity. Reverchon et al. developed RIF sub micronic particles $(400 \mathrm{~nm}$ to $3 \mu \mathrm{m})$ using supercritical carbon dioxide-assisted atomization suitable for parenteral and aerosolizable drug delivery systems. They studied effects of various solvents on resultant particle size and drug degradation suggesting use of nanoparticle production approach for more convenient TB pharmacotherapy administering drug locally to the lungs $[83,84]$. 


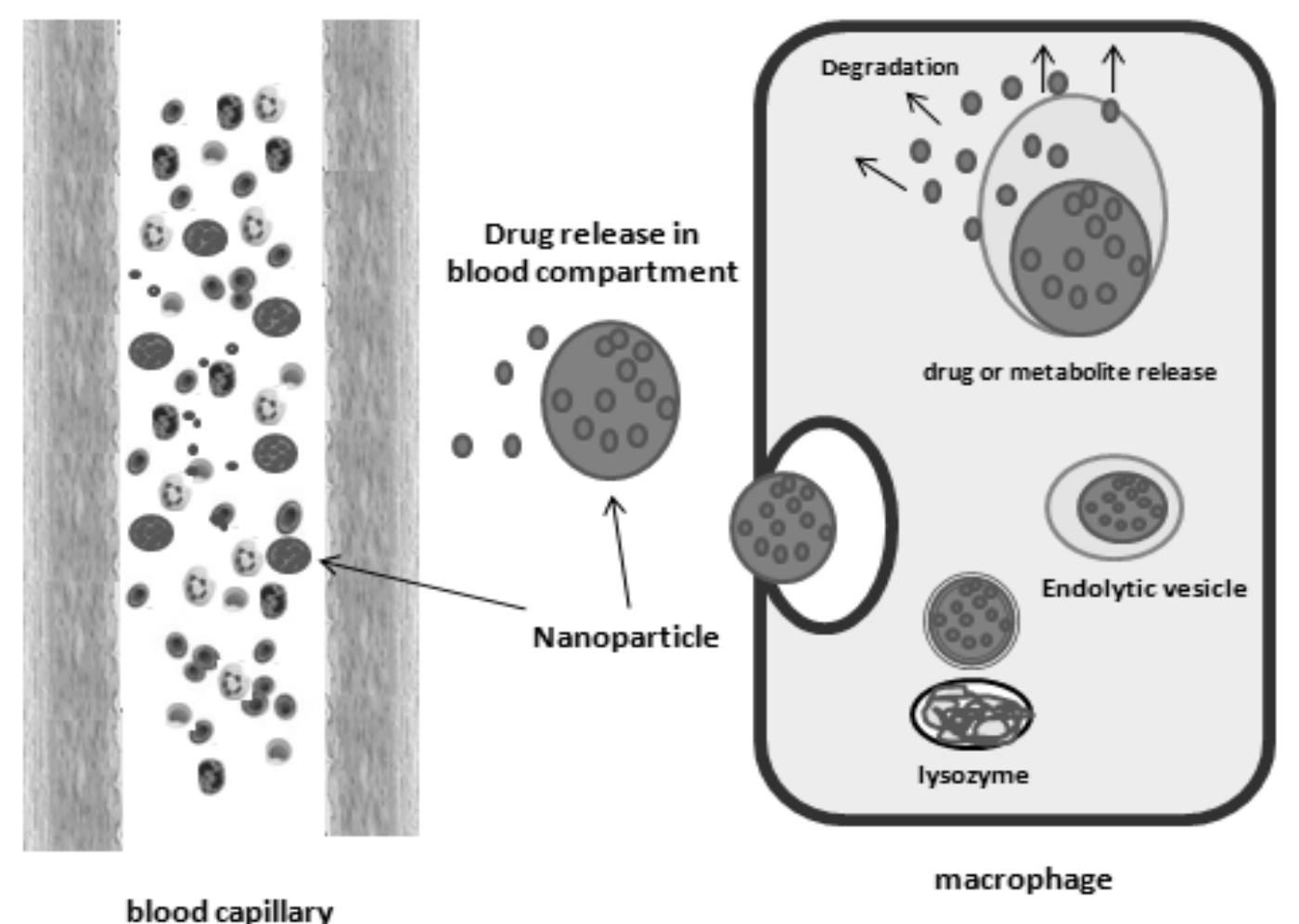

Figure 2. Proposed mechanism by which Nanoparticle encapsulated drug can be released in infected macrophage for anti-Tubercular treatment.

Hulda Swai's (CSIR's Centre for Polymer Technology, South Africa) team have developed nanoparticles $(200 \mathrm{~nm})$ of four frontline anti-TB drugs aiming to shorter treatment regimen with single dose drug application that will last for several days or weeks. They showed that the nanoparticles release the drugs into the bloodstream at a slower rate and for a more prolonged period (up to ten days) as compared to conventional therapy [85].

\section{Micelles}

Micelles are submicroscopic aggregates (20-80 $\mathrm{nm})$ of surfactant molecules resulting in liquid colloid. Jiang et al., synthesized thermoresponsive poly( $\varepsilon$-caprolactone-coglycolide)poly(ethylene glycol)-poly(e-caprolactone-coglycolide) (P(CL-GA)-PEG-P(CL-GA)) block copolymers having micelle- forming and gelation properties. They can be used for development of drug depot system. The sol-gel transition temperature was optimized by selecting optimized GA/CL ratio and length of the hydrophobic segments. RIF sustained release was obtained over 32 days from $25 \%$ gel matrix [30].
INH-poly(ethyleneglycol)-poly(aspartic acid) conjugates were studied for sustain release of the drug. A 5.6-fold increase in anti-tuberculosis activity against $M$. tuberculosis was found for micelle-forming prodrug as compared to the free drug [86]. Similar attempts were made to incorporate PYZ and RIF in micelles $(<100 \mathrm{~nm})$ aiming to minimize renal filtration and prolonging mean residence times in the blood stream with improved antimicrobial activity [87, 88]. INH lipid derivatives was designed by Jin et al. to reduce the resistance. The new amphiphilic molecules resulted in formation of monolayers at the air/water interface. Flexible medium-long tails formed self assembling nano-sized vesicles whereas short lipid tail-derivatives resulted in weak hydrophobic interactions. Lipid vesicles showed increased penetration of the drug into the pathogen leading to promising antibacterial activity against Mycobacterium [89].

Solubilization of RIF within polymeric micelles of various linear and branched PEOPPO was studied and found to increased about 2 fold depending upon RIF entrapment. Other studied amphiphilic block copolymers of different 
molecular weight further improved the solubilization of RIF by 5 to 7 fold [90]. Furthermore, drug-loaded stereocomplex micelles were developed by Chen et al. using the specific assembly of enantiomeric poly (ethylene glycol)poly(L-lactide) (MPEG-PLLA) and poly(ethylene glycol)-poly(D-lactide) (MPEG-PDLA) block copolymers (1:1 ratio of L-PLA- and D-PLAcontaining block copolymers). An increase in the length of the PLA segment resulted in lower CMC values and larger nano-aggregates. Developed stereocomplexes showed improved RIF loading and encapsulation efficiency than enantionerically pure micelles. Stereocomplex released $\mathrm{t}_{50 \%}$ between $4-8$ hours and $\mathrm{t}_{100 \%}$ after 48 $\mathrm{h}$, which can be further manipulated according to polymer molecular weight [91]. PLA-modified chitosan oligomers spherical micelles (154 to 181 $\mathrm{nm}$ ) were prepared by $\mathrm{Wu}$ et al. Developed RIF chitosan oligomer micelles showed initial burst drug release of $35 \%$ within $10 \mathrm{~h}$ followed by more sustained drug release till $5^{\text {th }}$ day suggesting suitability of carrier for prolonged anti-TB activity with reduced toxic effects [92].

Pulmonary tuberculosis causes lung fibrosis and alveolar collapse due to a dysfunction of pulmonary surfactant. Nanoparticles of pulmonary surfactant (surface tension of approx. $25-30 \mathrm{mN} / \mathrm{m}$ ) can be employed as delivery agents for the anti-tubercular drugs to the infected lung tissue. Anti-tubercular drug loaded surfactants nanoparticles for inhalation therapy were proposed by Chimote et al. These nanoparticles act as anti-atelectatic agents and can stabilize the alveoli integrity by preventing alveolar collapse thereby allowing drug to reach the diseased alveoli uniformly in a non-invasive manner. Such nanoparticulate aerosols would be a significant improvement over existing therapies in pulmonary tuberculosis [93, 94].

\section{Niosomes}

Niosomes has similarity to that of liposomes and they are mainly composed of non-ionic surfactant and with or without incorporation of lipids. Jain and Vyas prepared micro-sized $(8-15 \mu \mathrm{m})$ RIFloaded niosomes. In vivo studies revealed that, depending upon the size of niosomes, up to $65 \%$ of the drug can be localized in the lungs [95]. Niosomes $(1-2 \mu \mathrm{m})$ were prepared using sorbitan esters (Span ${ }^{\circledR}$ 20, 40, 60, 80 and 85) and cholesterol in a 50:50 percent mol fraction ratio [96]. They showed increase in entrapment efficiency with increase in hydrophobicity of the surfactant. In vivo biodistribution showed, higher
RIF concentrations in thoracic lymph nodes via the intraperitoneal route $(46.2 \%$ of the administered dose) for Niosomal formulations as compared to free drug (13.1\%). These findings suggested that compartmentalization of the drug took place in the lymphous tissue. The same formulation when injected intravenously, about $7.3 \%$ of the drug was found in the thorax with the accumulation level lower than the $11.5 \%$ obtained by free RIF. In another study, Mullaicharam and Murthy studied the organ biodistribution of RIF niosomes $(5 \mathrm{mg} / \mathrm{mL})$ and drug solution following intravenous and intratracheal administration in albino rats. Niosomes mainly accumulated in the lung, liver and kidney with the organ to serum AUC ratios being 117,060 for lung/serum, 67 for liver/serum and 3068 for kidney/serum following iv administration. In contrast, administration of free RIF resulted in a less selective delivery (558.3 for lung/serum, 16.1 for liver/serum and 332.6 for kidney/ serum). After intratracheal administration, niosomes showed 145-fold increase as compared to free drug, representing targeting potential of developed carriers [97]. In another study, RIF loaded Niosomes were prepared by reverse phase evaporation method and charge was induced by using Di Cetyl Phosphate [98]. Attempts were also made to incorporate INH in Niosomes [99, 100]

\section{Dendrimers}

Dendrimers represent a novel class of structurally controlled three dimensional macromolecules that radiate from a central core and are mainly derived from a branches-upon-branches structural design. Dendrimers are well defined, highly branched macromolecules. Kumar et al. developed mannosylated fifth generation (5G) PPI dendrimeric nanoparticles for delivery of RIF to macrophages. Drug encapsulation mainly depend on hydrophobic interactions and hydrogen bonding contributing to the physical binding of the drug to the core. High haemolysis levels were observed for amine-terminated dendrimers. Mannose on surface significantly reduced the haemolytic toxicity of the nanocarriers from 15.6 to $2.8 \%$. RIF-containing dendrimers reduced haemolytic effect of free RIF from 9.8 to $6.5 \%$. A similar effect was observed in epithelial cell line of kidney when tested for viability; encapsulation significantly improved the survival of the cells from approx. $50 \%$ (free RIF) to $85 \%$ ( RIF dendrimers). The phagocytic uptake of RIF and RIF-loaded dendrimers in alveolar macrophages harvested from rat lungs showed a clear increase 
in the intracellular concentration of the antibiotic [101]. A more recent reports investigated $4 \mathrm{G}$ and 5G PEGylated-PPI dendrimers for sustain the delivery of RIF. PEGylation resulted in a significant increase in drug entrapment for $4^{\text {th }}$ and $5^{\text {th }} \quad$ generation derivatives. PEG-grafted dendrimers showed low haemolytic activity (1$3 \%$ ) as composed the NH2-terminated ones (1420\%) [102]. Researchers from Monash Institute of Pharmaceutical Science (Melbourne, Australia) developed PEGylated Polylysine dendrimers in collaboration with Starpharma Holdings Ltd for cancer, HIV, tuberculosis and lymphatic disease conditions.

\section{Cyclodextrin inclusion complexes}

Complexation approach with Cyclodextrins (CD) was applied for encapsulation of RIF by means of different CD molecules. Ferreira et al., prepared inclusion complexes of RIF with hydroxyl propyl $\beta$ cyclodextrin (HP $\beta C D$ ) [103]. The complexation increased aqueous solubility of the drug linearly to the concentration of the $\mathrm{CD}$ used. The ${ }^{1} \mathrm{H}$ and ${ }^{15} \mathrm{~N}$ NMR analysis of free and complexed RIF revealed important changes in piperazine ring peaks of the drug, suggesting the interaction of this region with the hydrophobic core of HP $\beta C D$. Furthermore, UV analysis indicated an absence of strong bonding between the drug and the carrier [104].

Rao et al. compared complexation with $\beta-\mathrm{CD}$ and HP $\beta C D$ of RIF in order to improve the chemical stability and aqueous solubility of the drug. Phase solubility studies showed a 1:1 molar ratio was apparent; the stability constants found to be 58.13 and 76.37 for the pristine and the modified $\mathrm{CD}$, respectively indicating a stronger interaction between the drug and the HP $\beta C D$. IR spectroscopy further revealed that the interaction was through the piperazine group of RIF. All the complexes improved the thermal stability of the drug. Antibacterial activity was assayed in $\mathrm{M}$. tuberculosis for complexes showed a significant decrease in the MIC (minimum inhibitory concentration) from 64 to $32 \mu \mathrm{g} / \mathrm{mL}$, this could be due to a better permeation of the drug through the wall of the bacilli [105]. In another study, poorlywater soluble nitroimidazole P-824 (a new antiTB drug effect against drug-sensitive and multidrug resistant bacilli) HP- $\gamma-\mathrm{CD}$ complex showed reduction in bacterial load in the lungs at 50 and $100 \mathrm{mg} / \mathrm{kg}$ doses [106]. To enhance the pulmonary bioavailability of poorly soluble drugs with improved biocompatibility and reduced toxic effect have been investigated for local delivery of drugs to the lung [107]).

\section{Nanotoxicological issues}

Nanoparticles interact with living cell at different levels depending upon the size. Particle size play very important role while discussing about nanotoxicity. Various studies suggest that nanoparticles less than $100 \mathrm{~nm}$ can enter cells, those with diameters $<40 \mathrm{~nm}$ can enter the cell nucleus and those that are $<<35 \mathrm{~nm}$ can pass through the blood-brain barrier and enter the brain [108]. The knowledge about nanotoxicity help to identify the key safety issues in implementing nanoscience for health application, by investigating interaction of nanoparticles and biological systems (i.e., proteins, cells) and elucidating the relationship between the physical and chemical properties like size, shape, surface chemistry, composition, and aggregation with respect to toxic biological responses. Oxidative stress induced by nanoparticles can enhance inflammation through up regulation of redoxsensitive transcription. Nanoparticles can also alter mitochondrial function as well as cellular redox signaling. However, beside pharmacological activity, efficacy and pharmacokinetic studies it is very important to investigate toxicity effects of developed carrier systems at cellular level. Use of approved materials by official authority in development of carrier system would be helpful in minimizing toxic effects. International Alliance for Nano EHS Harmonization (IANH), working in direction of setting in vitro and in vivo nanomaterial Nano EHS testing protocols that are validated to produce the same results in multiple laboratories internationally and correlating the obtained results with obtained or predictive in-vivo data [109].

\section{New drug candidates in Clinical trials}

Currently available TB drug regimen is 40 years older comprising of administration of RIF and INH $[110,111]$. The WHO recommends DOTS (directly observed treatment, short course) which consist of combination of isoniazid, rifampicin, pyrazinamide and ethambutol or streptomycin (World Health Organization, 2010). Noncompliance to therapy causes MDR (multi drug resistant) and extensively drug resistant (XDR) TB strains for which the treatment last for 2 years. Most of the currently available anti-TB drugs are ineffective toward latent tuberculosis infections except RIF and PZA [112-114]. This generates need of more effective treatment with 
shorter duration and increased patient compliance. In this direction, various anti-TB drugs having novel mechanism of action have been synthesized and tested in-vitro. The American biolabs patented ASAP (silver) solutions for clinical treatment of various viral and bacterial diseases including TB $[115,116]$ and being sucessfully used in African hospitals to treat malaria, cholera, AIDS, flu, respiratory infections (pneumonia, bronchitis), tuberculosis, gonorrhea, MRSA (methicillin resistant staphylococcus aureaus), hepatitis etc. Currently, fluoroquinolones moxifloxacin and gatifloxacin, the diarylquinoline are going under clinical trials $[117,118]$. Clinical trials for Rifanano - a combination of the four main first-line TB drugs are scheduled in 2012 and the drug should be possibly available in government clinics by 2016. These drugs are coated with nano-sized particles with chemicals which will enable them to stick to the intestinal wall and release the drug for longer time [119]. A patent has been filed for compound, OPC-67683 (nitrodihydroimidazo-oxazole) by Otsuka Pharmaceutical Co., Ltd. in 2003 and in 2006, Phase I clinical trial was conducted in Japan. Otsuka filed a PCT patent application covering 2,3-dihydro-6-nitroimidazo- (2,1-b) oxazole compounds for TB treatment [120,121].

Recently Phase II trials were sucessfully completed for OPC- 67683 [122]. PA-824 (prodrug with long half life, inhibit bacterial cell wall lipid and protein synthesis) showed high invitro activity against $M$. tuberculosis and has not shown cross resistant to currant anti-TB drugs $[106,123]$. PA-824 is currently undergoing Phase II clinical trial (Golobal alliance for TB drug development, 2007). Whereas for SQ-109 (contains unsaturated isoprenyl units and adamantly ring) [124] completed Phase Ia trials in 2007 concluded that one-a week dosing may be achievable. Additional Phase Ib clinical study was performed to demonstrate safety of daily administration as single drug and as combination therapy to evaluate safety and efficacy in patients with pulmonary TB [124].

A diarylquinoline (DARQs) was being developed by Johnson \& Johnson as R207910 and Tibotec as TM207 [125]. It has higher potency against drug susceptible, MDR and XRD tuberculosis strains and is 100 times more effective than conventional combination of RIF, INH and PYZ [126]. Johnson \& Johnson found high bioavailability for TMC-07 oral solutions in clinical trials (Phase II). Hence studies on Solid dosage formulations are under development.
FASgen, Inc. is planning to conduct clinical trials on compound FAS $20013 \quad(90 \%$ orally bioavailable) which is very efficient to eliminate $>99 \%$ of bacilli (additionally latent bacilli) within 24 h [127]. Nitroimidazopyran PA824 was developed by the Global Alliance for Tuberculosis Drug Development. Linezolid, an oxazolidinone drug used in short-term for various bacterial infections including TB (clinical trial.gov identifier NCT00727844) and for mitronidazole for treatment of pulmonary tuberculosis (clinical trial.gov identifier NCT00425113) is under phase II trial. The bicyclic nitroimidazole PA-824 induces the killing of both replicating and non-replicating $\mathrm{M}$. tuberculosis is currently in Phase II clinical trials [128].

Other drug molecules are in various phases of preclinical and clinical trials and very little information is available. Lupin conducted multidose phase I clinical trial for a pyrrole derivative, LL-3858, an INH analogue (Sudoterb®) [129]. Another compound, OPC37306 is active against drug susceptible and resistant $M$. tuberculosis strains and was discovered in screening studies of the inhibition of mycolic acid biosysnthesis. SQ-609 acts by interfering in cell wall synthesis (Sequella Inc., 2007) while SQ641 inhibits enzyme translocase I which is required for synthesis of cell wall peptidoglycan [130]. Fluoroquninolines, capuramycins (RS-118641), oxazolidinones (Linezolid), beta-sulfonylcarboxamides, pleuromutilin, erytromycin and various other semisynthetic derivates of natural product rifampicin viz. rifapentine, rifabutin, rifalazil and rifametane are currently in various phase trial [131].

\section{CONCLUSIONS}

Developments in nanoparticle-based delivery systems represent a cost-effective, practical and promising alternative for potential TB chemotherapy. Improved drug bioavailability and reduction of the dosing frequency, feasibility of the versatile routes of drug administration, long term stability may serve as basis for better management of the disease. Nanoparticles can be incorporated into various solid dosage forms like tablet, capsules, microparticles \& granules would improve efficacy and practicability. The possibility of using drug carriers made from natural polymers (e.g., chitosan or alginate) represents an attractive perspective. 
Table 1: Various tubercular chemotherapeutic studies in clinical trial and their sponsors.

\begin{tabular}{ll}
\hline Aim of Study/drug candidate & Sponsor \\
\hline Metronidazole for Pulmonary TB (South Korea) & $\begin{array}{l}\text { National Institute of Allergy and Infectious } \\
\text { Diseases (NIAID) NCT00425113 }\end{array}$ \\
$\begin{array}{l}\text { Pharmacokinetics and Pharmacodynamics of High Versus Standard } \\
\text { Dose Rifampicin in Patients With Pulmonary TB (High RIF) }\end{array}$ & $\begin{array}{l}\text { African Poverty Related Infection Oriented } \\
\text { Research Initiative (NCT00760149) }\end{array}$
\end{tabular}

TMC207-C202: Study to Evaluate Bactericidal Activity of Multiple Oral Doses of TMC207 in Subjects With Sputum-Smear Positive TB

Treatment of Latent TB Infection With Isoniazid

A Randomized Clinical Trial Comparing 4RIF vs. 9INH for Treatment of Latent TB Infection (LTBI) - Effectiveness

Tuberculosis Treatment Shortening Trial

Linezolid to Treat Extensively-Drug Resistant TB

TBTC Study 29: Rifapentine During Intensive Phase TB Treatment

Rifapentine Plus Moxifloxacin for Treatment of Pulmonary TB

A Controlled Trial of a 4-Month Quinolone-Containing Regimen for the Treatment of Pulmonary TB

High-Dose Isoniazid Adjuvant Therapy for Multidrug Resistant Tuberculosis

Pharmacokinetic Study for Anti-tuberculosis Drugs (TBPK)

High Dose Rifapentine Pharmacokinetics, Tolerability and Safety Dosage Rifapentine for Treatment of TB (TBTC-29PK)

PA-824-CL-007: Phase IIa Evaluation of Early Bactericidal Activity in Pulmonary TB

TBTC Study 23: Treatment of HIV-Related TB Using a RifabutinBased Regimen

TBTC Study 27/28 PK: Moxifloxacin Pharmacokinetics During TB Treatment

Study of Daily Rifapentine for Pulmonary Tuberculosis

Randomized Trial for Pharmacogenomics-Based Tuberculosis Therapy (RT-PGTT)
Tibotec BVBA (NCT00523926)

Instituto Nacional de Salud Publica, Mexico (NCT00293228)

McGill University (NCT00931736)

National Institute of Allergy and Infectious Diseases (NIAID) NCT00130247

National Institute of Allergy and Infectious Diseases (NIAID) NCT00727844

Centers for Disease Control and Prevention NCT00694629

Johns Hopkins University NCT00728507

Institut de Recherche pour le Developpement (NCT00216385)

GSVM Medical College NCT00513396

Taipei Medical University WanFang Hospital (NCT00948077)

Centers for Disease Control and Prevention (NCT01043575)

Global Alliance for TB Drug Development (NCT00567840)

Centers for Disease Control and Prevention (NCT00023361)

Centers for Disease Control and Prevention (NCT00164463)

Johns Hopkins University

(NCT00814671)

Osaka University

(NCT00298870) 


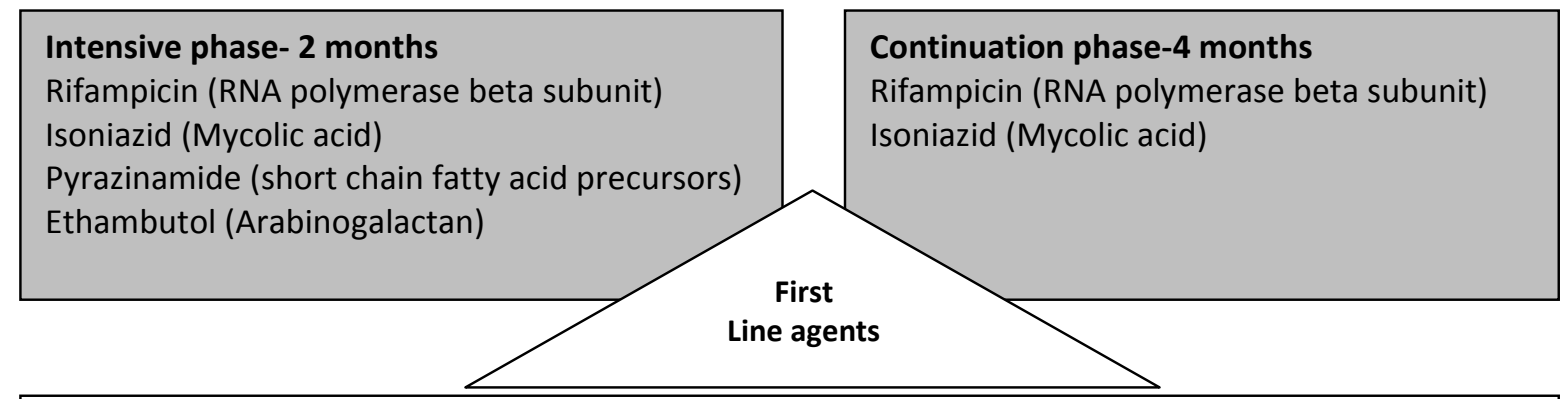

\section{Other drugs}

Aminoglycosides (inhibition of protein synthesis through binding to $30 \mathrm{~S}$ subunit ribosomal proteins)

e.g. Streptomycin, Kanamycin, capreomycin, Rifabutin

Fluoroquinolones (inhibition of DNA synthesis)

Ciprofloxacin, ofloxacin, levofloxacin, motifloxacin, gatifloxacin, sparfloxacin

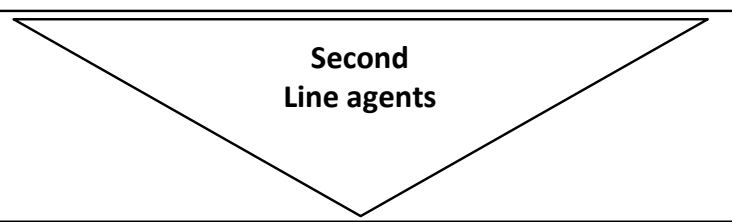

Bacteriostatic drugs

Clofazimine (interfere with DNA binding) and Amikacin, Linezolid

Clarithromycin (inhibition of protein synthesis via binding to 50Sribosomal RNA)

Ethionamide (blocks synthesis of Mycolic acids)

Cycloserine (inhibihition of alanine racemase)

P-aminosalicylic acid (interfere with incorporation of para-aminobenzoic acid into folic acid)

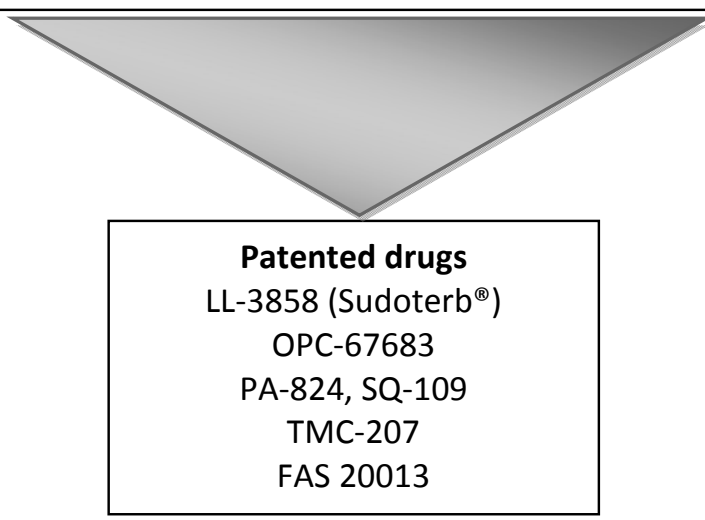

Fig.3: List of drugs (along with site of action) used in TB chemotherapy and patented new drugs

\section{REFERENCES}

1. Padayatchi N,Friedland G. Decentralised management of drug-resistant tuberculosis (MDRand XDR-TB) in South Africa: an alternative model of care. Int J Tuberc Lung Dis, 2008; 12: 978-980.
2. Singh JA, Upshur R,Padayatchi N. XDR-TB in South Africa: no time for denial or complacency. PLoS Med, 2007; 4: e50.

3. Maartens G.,Wilkinson R.J. Tuberculosis. Lancet, 2007; 370: 2030-2043.

4. Harries AD,Dye C. Tuberculosis. Ann Trop Med Parasitol, 2006; 100: 415-431. 
5. Onyebujoh P,Rook GAW. Tuberculosis. Nature Reviews Microbiology, 2004; 2: 930-993.

6. Skeiky YA,Sadoff JC. Advances in tuberculosis vaccine strategies. Nature Reviews Microbiology, 2006; 4: 469-476.

7. du Toit LC, Pillay V,Danckwerts MP. Tuberculosis chemotherapy: current drug delivery approaches. Respir Res, 2006; 7: 118.

8. Aagaard C, Dietrich J, Doherty M,Andersen P. TB vaccines: current status and future perspectives. Immunol Cell Biol, 2009; 87: 279-286.

9. Schatz A, Bugie E,Waksman SA. Streptomycin, a substance exhibiting antibiotic activity against gram-positive and gram-negative bacteria. Clin Orthop Relat Res, 2005: 3-6.

10. Kaufmann SHE. How can immunology contribute to the control of tuberculosis? Nature Reviews Immunology, 2001; 1: 20-30.

11. Orme IM. Tuberculosis vaccines: current progress. Drugs, 2005; 65: 2437-2444.

12. Vordermeier HM, Chambers MA, Buddle BM, Pollock JM,Hewinson RG. Progress in the development of vaccines and diagnostic reagents to control tuberculosis in cattle. Vet J, 2006; 171: 229-244.

13. Romano M, Roupie V, Wang XM, Denis O, Jurion F, Adnet PY, Laali R,Huygen K. Immunogenicity and protective efficacy of tuberculosis DNA vaccines combining mycolyltransferase Ag85A and phosphate transport receptor PstS-3. Immunology, 2006; 118: 321332.

14. D'Souza S, Rosseels V, Denis O, Tanghe A, De Smet N, Jurion F, Palfliet K, Castiglioni N, Vanonckelen A, Wheeler C,Huygen K. Improved tuberculosis DNA vaccines by formulation in cationic lipids. Infect Immun, 2002; 70: 36813688.

15. Zaks K, Jordan M, Guth A, Sellins K, Kedl R, Izzo A, Bosio C,Dow S. Efficient immunization and cross-priming by vaccine adjuvants containing TLR3 or TLR9 agonists complexed to cationic liposomes. J Immunol, 2006; 176: 7335-7345.

16. Rosada RS, de la Torre LG, Frantz FG, Trombone AP, Zarate-Blades CR, Fonseca DM, Souza PR, Brandao IT, Masson AP, Soares EG, Ramos SG, Faccioli LH, Silva CL, Santana MH,CoelhoCastelo AA. Protection against tuberculosis by a single intranasal administration of DNA-hsp65 vaccine complexed with cationic liposomes. BMC Immunol, 2008; 9: 38.

17. Garcia-Contreras L, Wong YL, Muttil P, Padilla D, Sadoff J, Derousse J, Germishuizen WA, Goonesekera S, Elbert K, Bloom BR, Miller R, Fourie PB, Hickey A,Edwards D. Immunization by a bacterial aerosol. Proc Natl Acad Sci U S A, 2008; 105: 4656-4660.

18. Condos R, Rom WN,Schluger NW. Treatment of multidrug-resistant pulmonary tuberculosis with interferon-gamma via aerosol. Lancet, 1997; 349: 1513-1515.

19. Reljic R. IFN-gamma therapy of tuberculosis and related infections. J Interferon Cytokine Res, 2007; 27: 353-364.

20. Manolova V, Flace A, Bauer M, Schwarz K, Saudan P,Bachmann MF. Nanoparticles target distinct dendritic cell populations according to their size. Eur J Immunol, 2008; 38: 1404-1413.

21. Sakagami M. In vivo, in vitro and ex vivo models to assess pulmonary absorption and disposition of inhaled therapeutics for systemic delivery. Advance Drug Delivery Reviews, 2006; 58: 10301060 .

22. Smola M, Vandamme T,Sokolowski A. Nanocarriers as pulmonary drugdelivery systems to treat and to diagnose respiratory and non respiratory diseases. Int J Nanomedicine, 2008; 3: 1-19.

23. Scheuch G, Kohlhaeufl MJ, Brand P,Siekmeier R. Clinical perspectives on pulmonary systemic and macromolecular delivery. Advance Drug Delivery Reviews, 2006; 58: 996-1008.

24. Mitchison DA,Fourie PB. The near future: improving the activity of rifamycins and pyrazinamide. Tuberculosis (Edinb), 2010; 90: 177-181.

25. Fiegel J, Garcia-Contreras L, Thomas M, VerBerkmoes J, Elbert K, Hickey A,Edwards D. Preparation and in vivo evaluation of a dry powder for inhalation of capreomycin. Pharm Res, 2008; 25: 805-811.

26. Garcia-Contreras L, Fiegel J, Telko MJ, Elbert K, Hawi A, Thomas M, VerBerkmoes J, Germishuizen WA, Fourie PB, Hickey AJ,Edwards D. Inhaled large porous particles of capreomycin for treatment of tuberculosis in a guinea pig model. Antimicrob Agents Chemother, 2007; 51: 2830-2836.

27. Tsapis N, Bennett D, O'Driscoll K, Shea K, Lipp MM, Fu K, Clarke RW, Deaver D, Yamins D, Wright J, Peloquin CA, Weitz DA,Edwards DA. Direct lung delivery of para-aminosalicylic acid by aerosol particles. Tuberculosis (Edinb), 2003; 83: 379-385.

28. Gaur PK, Mishra S, Gupta VB, Rathod MS, Purohit S,Savla BA. Targeted drug delivery of Rifampicin to the lungs: formulation, characterization, and stability studies of preformed aerosolized liposome and in situ formed aerosolized liposome. Drug Dev Ind Pharm, 2010; 36: 638-646.

29. Date AA, Joshi MD,Patravale VB. Parasitic diseases: Liposomes and polymeric nanoparticles versus lipid nanoparticles. Advance Drug Delivery Reviews, 2007; 59: 505-521.

30. Jiang W, Kim BY, Rutka JT,Chan WC. Advances and challenges of nanotechnology-based drug delivery systems. Expert Opin Drug Deliv, 2007; 4: 621-633. 
31. Kaur K, Gupta A, Narang RK,Murthy RSR. Novel drug delivery systems: desired feat for tuberculosis. Journal of Advanced Pharmaceutical Technology and Research, 2010; 1: 145-163.

32. Pandey R,Khuller GK. Nanotechnology base drug delivery system(s) for the management of tuberculosis. Indian J Exp Biol, 2006; 44: 357 366.

33. Suri SS, Fenniri H,Singh B. Nanotechnologybased drug delivery systems. J Occup Med Toxicol, 2007; 2: 16.

34. Gelperina S, Kisich K, Iseman MD,Heifets L. The potential advantages of nanoparticle drug delivery systems in chemotherapy of tuberculosis. Am J Respir Crit Care Med, 2005; 172: 1487-1490.

35. Kreuter J; Nanoparticles as drug delivery system. Encyclopedia of Nanoscience and Nanotechnology, ed. In: Nalwa H S. Vol. 7. 2004, New York: American Scientific Publishers.

36. Müller RH, Mehnert W, Lucks JS, Schwarz C, zur Mühlen A, Weyhers H, Freitas C,Ruhl D. Solid Lipid Nanoparticles (SLN) - an Alternative Colloidal Carrier System for Controlled DrugDelivery. Eur J Pharm Biopharm, 1995; 41: 62-69.

37. Wissing SA, Kayser O,Müller RH. Solid lipid nanoparticles for parenteral drug delivery. Advance Drug Delivery Reviews, 2004; 56: 1257 1272.

38. Florence AT. Issues in oral nanoparticle drug carrier uptake and targeting. J Drug Target, 2004; 12: $65-70$.

39. Florence AT,Hussain N. Transcytosis of nanoparticle and dendrimer delivery systems: evolving vistas. Advance Drug Delivery Reviews, 2001; 50 Suppl 1: S69-89.

40. Khuller GK, Kapur M,Sharma S. Liposome technology for drug delivery against mycobacterial infections. Curr Pharm Des, 2004; 10: 3263-3274.

41. Salem, II, Flasher DL,Duzgunes N. Liposomeencapsulated antibiotics. Methods Enzymology, 2005; 391: 261-291.

42. Klemens SP, Cynamon MH, Swenson CE,Ginsberg RS. Liposome-encapsulatedgentamicin therapy of Mycobacterium avium complex infection in beige mice. Antimicrob Agents Chemother, 1990; 34: 967-970.

43. Duzgunes N, Flasher D, Reddy MV, Luna-Herrera J,Gangadharam PR. Treatment of intracellular Mycobacterium avium complex infection by free and liposome-encapsulated sparfloxacin. Antimicrob Agents Chemother, 1996; 40: 26182621.

44. Leitzke S, Bucke W, Borner K, Muller R, Hahn H,Ehlers S. Rationale for and efficacy of prolonged-interval treatment using liposomeencapsulated amikacin in experimental Mycobacterium avium infection. Antimicrob Agents Chemother, 1998; 42: 459-461.
45. Oh YK, Nix DE,Straubinger RM. Formulation and efficacy of liposome-encapsulated antibiotics for therapy of intracellular Mycobacterium avium infection. Antimicrob Agents Chemother, 1995; 39: 2104-2111.

46. Deol P,Khuller GK. Lung specific stealth liposomes: stability, biodistribution and toxicity of liposomal antitubercular drugs in mice. Biochim Biophys Acta, 1997; 1334: 161-172.

47. Deol P, Khuller GK,Joshi K. Therapeutic efficacies of isoniazid and rifampin encapsulated in lung-specific stealth liposomes against Mycobacterium tuberculosis infection induced in mice. Antimicrob Agents Chemother, 1997; 41: 1211-1214.

48. Mehta RT, Keyhani A, McQueen TJ, Rosenbaum $\mathrm{B}$, Rolston KV,Tarrand JJ. In vitro activities of free and liposomal drugs against Mycobacterium avium-M. intracellulare complex and $M$. tuberculosis. Antimicrob Agents Chemother, 1993; 37: 2584-2587.

49. Adams LB, Sinha I, Franzblau SG, Krahenbuhl JL,Mehta RT. Effective treatment of acute and chronic murine tuberculosis with liposomeencapsulated clofazimine. Antimicrobial Agents \& Chemotherapy., 1999; 43: 1638-1643.

50. El-Ridy MS, Mostafa DM, Shehab A, Nasr EA,Abd El-Alim S. Biological evaluation of pyrazinamide liposomes for treatment of Mycobacterium tuberculosis. Int J Pharm, 2007; 330: 82-88.

51. Gaspar MM, Cruz A, Penha AF, Reymao J, Sousa $\mathrm{AC}$, Eleuterio $\mathrm{CV}$, Domingues SA, Fraga AG, Filho AL, Cruz ME,Pedrosa J. Rifabutin encapsulated in liposomes exhibits increased therapeutic activity in a model of disseminated tuberculosis. Int J Antimicrob Agents, 2008; 31: $37-45$.

52. Shafiq S, Shakeel F, Talegaonkar S, Ahmad FJ, Khar RK,Ali M. Development and bioavailability assessment of ramipril nanoemulsion formulation. Eur J Pharm Biopharm, 2007; 66: 227-243.

53. Shafiq S,Shakeel F. Effect of Labrasol on selfnanoemulsification efficiency of ramipril nanoemulsion. Pharmazie, 2009; 64: 812-817.

54. Ahmed M, Ramadan W, Rambhu D,Shakeel F. Potential of nanoemulsions for intravenous delivery of rifampicin. Pharmazie, 2008; 63: 806811.

55. Mehta SK, Kaur G,Bhasin KK. Incorporation of antitubercular drug isoniazid in pharmaceutically accepted microemulsion: effect on microstructure and physical parameters. Pharm Res, 2008; 25: 227-236.

56. Mehta SK, Kaur G,Bhasin KK. Tween-embedded microemulsions--physicochemical and spectroscopic analysis for antitubercular drugs. AAPS PharmSciTech, 2010; 11: 143-153.

57. Soppimath KS, Aminabhavi TM, Kulkarni AR,Rudzinski WE. Biodegradable polymeric 
nanoparticles as drug delivery devices. J Control Release, 2001; 70: 1-20.

58. Bala I, Hariharan S,Kumar MN. PLGA nanoparticles in drug delivery: the state of the art. Crit Rev Ther Drug Carrier Syst, 2004; 21: 387422.

59. Pandey R, Sharma A, Zahoor A, Sharma S, Khuller GK,Prasad B. Poly (DL-lactide-coglycolide) nanoparticle-based inhalable sustained drug delivery system for experimental tuberculosis. J Antimicrob Chemother, 2003; 52: 981-986.

60. Sharma A, Pandey R, Sharma S,Khuller GK. Chemotherapeutic efficacy of poly (DL-lactideco-glycolide) nanoparticle encapsulated antitubercular drugs at sub-therapeutic dose against experimental tuberculosis. Int $\mathrm{J}$ Antimicrob Agents, 2004; 24: 599-604.

61. Ain Q, Sharma S, Garg SK,Khuller GK. Role of poly [DL-lactide-co-glycolide] in development of a sustained oral delivery system for antitubercular drug(s). Int J Pharm, 2002; 239: 37-46.

62. Dutt M,Khuller GK. Chemotherapy of Mycobacterium tuberculosis infections in mice with a combination of isoniazid and rifampicin entrapped in Poly (DL-lactide-co-glycolide) microparticles. J Antimicrob Chemother, 2001; 47: 829-835.

63. Sharma A, Sharma S,Khuller GK. Lectinfunctionalized poly (lactide-coglycolide) nanoparticles as oral/aerosolized antitubercular drug carriers for treatment of tuberculosis. J Antimicrob Chemother, 2004; 54: 761-766.

64. Gabor F, Bogner E, Weissenboeck A,Wirth M. The lectin-cell interaction and its implications to intestinal lectin-mediated drug delivery. Advance Drug Delivery Reviews, 2004; 56: 459-480.

65. Pandey R,Khuller GK. Antitubercular inhaled therapy: opportunities, progress and challenges. J Antimicrob Chemother, 2005; 55: 430-435.

66. Condos R,Schluger NW. Cytokine-based approaches to the treatment of multidrug-resistant tuberculosis. BioDrugs, 1999; 11: 165-173.

67. Johnson BJ, Bekker LG, Rickman R, Brown S, Lesser M, Ress S, Willcox P, Steyn L,Kaplan G. rhuIL-2 adjunctive therapy in multidrug resistant tuberculosis: a comparison of two treatment regimens and placebo. Tuber Lung Dis, 1997; 78: 195-203.

68. Ohashi K, Kabasawa T, Ozeki T,Okada H. Onestep preparation of rifampicin/poly (lactic-coglycolic acid) nanoparticle-containing mannitol microspheres using a four-fluid nozzle spray drier for inhalation therapyof tuberculosis. J Control Release, 2009; 135 19-24.

69. Pandey R,Khuller GK. Subcutaneous nanoparticle-based antitubercular chemotherapy in an experimental model. J Antimicrob Chemother, 2004; 54: 266-268.
70. Anisimova YV, Gelperina SE, Peloquin CA,Heifets IB. nanoparticles as antituberculosis drugs carriers: effect on activity against $\mathrm{m}$. tuberculosis in human monocyte-derived macrophages. Journal of Nanoparticle Research, 2000; 2: 165-171.

71. Kisich KO, Gelperina SI, Higgins MP, Wilson S, Shipulo E, Oganesyan E,Heifets LB. Encapsulation of moxifloxacin within poly(butyl cyanoacrylate) nanoparticles enhances efficacy against intracellular Mycobacterium tuberculosis. Int J Pharm, 2007; 345 154-162.

72. Zahoor A, Pandey R, Sharma S,Khuller GK. Pharmacokinetic and pharmacodynamic behavior of antitubercular drugs encapsulated in alginate nanoparticles at two doses. Int $\mathrm{J}$ Antimicrob Agents, 2006; 27: 409-416.

73. du Toit LC, Pillay V, Choonara YE,Iyuke SE. Formulation and evaluation of a salted-out isoniazid-loaded nanosystem. AAPS PharmSciTech, 2008; 9: 174-181.

74. Gangadharam PR, Geeta N, Hsu YY,Wise DL. Chemotherapy of tuberculosis in mice using single implants of Isoniazid and pyrazinamide. Int $\mathrm{J}$ Tuberc Lung Dis, 1999; 3: 515-520.

75. Kailasam S, Daneluzzi D,Gangadharam PR. Maintainance of therapeutically active levels of isoniazid for prolonged periods in rabbits after a single implant of biodegradable polymer. Tuber Lung Dis, 1994; 75: 361-365.

76. Reddy ST, van der Vlies AJ, Simeoni E, Angeli V, Randolph GJ, O'Neil CP, Lee LK, Swartz MA,Hubbell JA. Exploiting lymphatic transport and complement activation in nanoparticle vaccines. Nat Biotechnol, 2007; 25: 1159-1164.

77. Song HY, Ko KK, Oh IH,Lee BT. Frabrication of silver nanoparticles and their antimicrobial mechanisms. Eur Cell Mater, 2006; 11: 58.

78. Bummer PM. Physical chemical considerations of lipid-based oral drug delivery--solid lipid nanoparticles. Crit Rev Ther Drug Carrier Syst, 2004; 21: 1-20.

79. Pandey R, Sharma S,Khuller GK. Oral solid lipid nanoparticles-based antitubecular chemotherapy. Tuberculosis, 2005; 85: 415-420.

80. Shegokar R,Müller RH. Nanocrystals: Industrially feasible multifunctional formulation technology for poorly soluble actives. Int J Pharm, 2010; 399: 129-139.

81. Rabinow BE. Nanosuspensions in drug delivery. Nature Reviews Drug Discovery, 2004; 3: 785 796.

82. Peters K, Leitzke S, Diederichs JE, Borner K, Hahn H, Müller RH,Ehlers S. Preparation of a clofazimine nanosuspension for intravenous use and evaluation of its therapeutic efficacy in murine Mycobacterium avium infection. J Antimicrob Chemother, 2000; 45: 77-83.

83. Reverchon E, De Marco I,Della Porta G. Rifampicin microparticles production by 
supercritical antisolvent precipitation. Int J Pharm, 2002; 243: 83-91.

84. Reverchon E,Della Porta G. Micronization of antibiotics by supercritical assisted atomization. Journal of Supercritical Fluids, 2003: 243-252.

85. Swai H, Semete B, Kalombo L,Chelule P. Potential of treating tuberculosis with a polymeric nano-drug delivery system. J Control Release, 2008; 132: e48.

86. Silva M, Lara AS, Leite CQF,Ferreira EI. Potential tuberculostatic agents: micelle-forming copolymer poly(ethylene glycol)-poly(aspartic acid) prodrug with isoniazid. Arch. Pharm. Pharm. Med. Chem., 2001; 334: 189-193.

87. Silva M, Ferreira EI, Leite CQF,Sato DN. Preparation of polymeric micelles for use as carriers of tuberculostatic drugs. Tropical Journal of Pharmaceutical Research, 2007; 6: 815-824.

88. Silva M, Ricelli NL, El Seoud O, Valentim CS, Ferreira AG, Sato DN, Leite CQF,Ferreira EI. Potential tuberculostatic agent: micelle-forming pyrazinamide prodrug. Arch. Pharm. Chem. Life Sci., 2006; 339: 283-290.

89. Jin Y, Chen S, Xin R,Zhou Y. Monolayers of the lipid derivatives of isoniazid at the air/water interface and the formation of self-assembled nanostructures in water. Colloids Surf., B Biointerfaces, 2008; 64: 229-235.

90. Moretton MA, Glisoni RJ, Chiappetta DA,Sosnik A. Synthesis and characterization of amphiphilic poly/epsilon-caprolactone)-poly(ethyleneglycol) block copolymers, optimization of the solubility and stability of rifampicin bymeans of encapsulation. in into polymeric micelles, BIOOMAT 2009, I Workshop on Artificial Organs, Biomaterials and Tissue EngineeringLatin American Society of Biomaterials, Tissue Engineering and Artificial Organs (SLABO). 2009. Rosario, Argentina.

91. Chen L, Xie Z, Hu J, Chen X,Jing X. Enantiomeric PLA-PEG block copolymers and their stereocomplex micelles used as rifampin delivery. Journal of Nanoparticle Research, 2007; 9: 777-785.

92. Wu Y, Li M,Gao H. Polymeric micelle composed of PLA and chitosan as a drug carrier. Journal of Polymer Research, 2009; 16: 11-18.

93. Chimote G,Banerjee R. Effect of antitubercular drugs on dipalmitoyl phosphatidylcholine monolayers: implication for drug loaded surfactants. Respiration Physiology and Neurobiology, 2005; 145: 65-77.

94. Chimote G,Banerjee R. Evaluation of antitubercular drug-loaded surfactants as inhalable drug-delivery systems for pulmonary tuberculosis. Journal of Biomedical Materials Research Part A, 2009; 89: 281-292.

95. Jain CP,Vyas SP. Preparation and characterization of niosomes containing rifampicin for lung targeting. J Microencapsul, 1995; 12: 401-407.
96. Jain CP, Vyas SP,Dixit VK. Niosomal system for delivery of rifampicin to lymphatics. Indian Journal of Pharmaceutical Sciences, 2006; 68: 575-578.

97. Mullaicharam AR,Murthy RSR. Lung accumulation of niosome-entrapped rifampicin following intravenous and intratracheal administration in the rat. Journal of Drug Delivery Sciences and Technology, 2004; 14: 99-104.

98. Singh G, Raghuvanshi HK, Anand A, Pundir R,Dwivedi H. Targeted Delivery of Rifampicin by Niosomal Drug Delivery System. Journal of Pharmacy Research, 2010; 3: 1152-1154.

99. Mostafa Mohamed YM, Study of Niosomal encapsulation of the antitubercular drugs, Isoniazid. 2010, University of Cairo, M.Sc. thesis.

100.Karki R, Mamatha GC, Subramanya G,Udupa N. Preparation, characterization and tissue disposition of niosomes containing isoniazid. Rasayan Journal of Chemistry, 2008; 2: 224-227.

101.Kumar PV, Asthana A, Dutta T,Jain NK. Intracellular macrophage uptake of rifampicin loaded mannosylated dendrimers. J Drug Target, 2006; 14: 546-556.

102.Kumar PV, Agashe H, Dutta T,Jain NK. PEGylated dendritic architecture for development of a prolonged drug delivery system for an antitubercular drug. Curr Drug Deliv, 2007; 4: 1119.

103.Ferreira DA, Ferreira AG, Vizzotto L, Federman Neto A,Gomes de Oliveira A. Analysis of the molecular association of rifampicin with hydroxypropyl- $\beta$ - cyclodextrin. Brazilian Journal of Pharmaceutical Sciences, 2004; 40: 43-51.

104. Mehta SK, Bhasin KK, Mehta N,Dham S. Behavior of rifampicin in association with $\beta$ cyclodextrin in aqueous media: a spectroscopic and conductometric study. Colloid and Polymer Science, 2005; 283: 532-538.

105.Rao PB, Suresh S,Balasangameshwer NC. Physicochemical characterization of $\beta$ cyclodextrin and hydroxy ethyl $\beta$-cyclodextrin complexes of rifampicina. Ars Pharmaceutica, 2006; 47: 37-59.

106.Lenaerts AJ, Gruppo V, Marietta KS, Johnson CM, Driscoll DK, Tompkins NM, Rose JD, Reynolds RC,Orme IM. Preclinical testing of the nitroimidazopyran PA-824 for activity against Mycobacterium tuberculosis in a series of in vitro and in vivo models. Antimicrob Agents Chemother, 2005; 49: 2294-2301.

107.Evrard B, Bertholet P, Gueders M, Flament MP, Piel G, Delattre L, Gayot A, Leterme P, Foidart JM,Cataldo D. Cyclodextrins as a potential carrier in drug nebulization. J Control Release, 2004; 96: 403-410.

108.Dawson KA, Salvati A,Lynch I. Nanotoxicology: nanoparticles reconstruct lipids. Nat Nanotechnol, 2009; 4: 84-85. 
109.New Nanotoxicity Research Effort. http://www.nanolawreport.com/2008/09/articles/n ew-nanotoxicity-research-effort/, 2008.

110.Janin YL. Antituberculosis drugs: ten years of research. Bioorg Med Chem, 2007; 15: 24792513.

111. Onyebujoh P, Zumla A, Ribeiro I, Rustomjee R, Mwaba P, Gomes M,Grange JM. Treatment of tuberculosis: present status and future prospects. Bull World Health Organ, 2005; 83: 857-865.

112.Bishai WR,Chaisson RE. Short-course chemoprophylaxis for tuberculosis. Clin Chest Med, 1997; 18: 115-122.

113. Cowie RL. Short course chemoprophylaxis with rifampicin, isoniazid and pyrazinamide for tuberculosis evaluated in gold miners with chronic silicosis: a double-blind placebo controlled trial. Tuber Lung Dis, 1996; 77: 239-243.

114. Smith CV, Sharma V,Sacchettini JC. TB drug discovery: addressing issues of persistence and resistance. Tuberculosis (Edinb), 2004; 84: 45-55.

115.Holladay RJ, Christensen H,Moeller WD, Apparatus and method for producing antimicrobial silver solution, US patent 6,743,348. 2004.

116.Holladay RJ, Christensen H,Moeller WD, Treatment of humans with colloidal silver composition, US patent 7,135,195. 2006.

117. Davies GR. Early clinical development of antituberculosis drugs: science, statistics and sterilizing activity. Tuberculosis (Edinb), 2010; 90: 171-176.

118. Mitchison DA. Clinical development of antituberculosis drugs. J Antimicrob Chemother, 2006; 58: 494-495.

119. Weblink

1.

http://www.scidev.net/en/news/scientists-use-

nanotech-to-upgrade-tb-drugs.html, retried on 14 august 2010.

120. Matsumoto $M$, Hashizume $H$, Tomishige $T$, Kawasaki M, Tsubouchi H, Sasaki H, Shimokawa Y,Komatsu M. OPC-67683, a nitro-dihydroimidazooxazole derivative with promising action against tuberculosis in vitro and in mice. PLoS Med, 2006; 3: e466.

121.Opc-67683. Tuberculosis (Edinb), 2008; 88: 132133.
122. Otsuka Frankfurt Research Institute $\mathrm{GmbH}$. Safety, efficacy and pharmacokinetics of OPC67683 in patients with pulmonary tuberculosis. ClinicalTrials.gov, US National Library of Medicine, 2007.

123. Stover CK, Warrener $\mathrm{P}$, VanDevanter DR, Sherman DR, Arain TM, Langhorne MH, Anderson SW, Towell JA, Yuan Y, McMurray DN, Kreiswirth BN, Barry CE,Baker WR. A small-molecule nitroimidazopyran drug candidate for the treatment of tuberculosis. Nature, 2000; 405: 962-966.

124.Sequella Inc. Product pipeline, product summaries. www.sequella.com, 2007.

125.Tibotec Pharmaceuticals Limited. Antibacterial activity, safety and tolerability of TMC 207 in patients with multidrug resistant Mycobacterium tuberculosis (MDR-TB). ClinicalTrials.gov, US National Library of Medicine, 2007; www.clinicaltrials.gov/ct/show/NCT00449644?or der $=1$.

126.Lenaerts AJ, Hoff D, Aly S, Ehlers S, Andries K, Cantarero L, Orme IM,Basaraba RJ. Location of persisting mycobacteria in a Guinea pig model of tuberculosis revealed by $\mathrm{r} 207910$. Antimicrob Agents Chemother, 2007; 51: 3338-3345.

127.FASgen. TB therapeutics from FASgen. www.fasgen.com/pipeline-fr.html, 2007.

128. NIH.

http://www.niaid.nih.gov/labsandresources/labs/a boutlabs/lcid/tuberculosisresearchsection/Pages/b arry.aspx, retried on 14th August, 2010.

129. Arora SK, Sinha N, Jain S, Upadhayaya RS, Jana G, Shankar A,Sinha RK, Pyrrole Derivatives as antimycobacterial compounds, International Patent WO/2004/026828, Lupin Limited. 2004.

130.Brandish PE, Kimura KI, Inukai M, Southgate R, Lonsdale JT,Bugg TD. Modes of action of tunicamycin, liposidomycin $\mathrm{B}$, and mureidomycin A: inhibition of phospho- $\mathrm{N}$-acetylmuramylpentapeptide translocase from Escherichia coli. Antimicrob Agents Chemother, 1996; 40: 16401644.

131.Gutierrez-Lugo MT,Bewley CA. Natural products, small molecules, and genetics in tuberculosis drug development. J Med Chem, 2008; 51: 2606-2612. 